\title{
ENSINO DE GRAMÁTICA NA EDUCAÇÃO BÁSICA: UM OLHAR REFLEXIVO SOBRE AS ABORDAGENS METODOLÓGICAS EM SALA DE AULA
}

\author{
Grammar teaching in Basic Education: a reflective look at methodological approaches in the classroom
}

\author{
Damarys Alves da Silva Barbosa ${ }^{1}$
}

Francisco Renato Lima²

\begin{abstract}
RESUMO: O presente estudo discute sobre o ensino de gramática na Educação Básica e como ele pode ser desenvolvido diante das diferentes concepções teórico-metodológicas que sustentam as práticas de ensino da língua materna na escola. Aponta-se, diante desse cenário, para a possibilidade de ensinar gramática de forma reflexiva para o aluno, afastando-se da abordagem de ensino tradicional, de base estruturalista, que historicamente se assentou sobre os bancos escolares. Objetiva-se, com isso, neste estudo, realizar uma reflexão sobre o ensino da língua e de que maneira se deve passar o conceito de gramática para o aluno, sem menosprezar os outros tipos de linguagem que se distanciam da norma padrão, ou seja, ensinar a gramática de forma que o sujeito respeite e saiba se expressar diante das variações linguísticas face às diversas situações de uso da língua, desde as variedades cultas, consideradas padrão às variedades menos prestigiadas, consideradas informais. Metodologicamente, partiu-se de uma pesquisa bibliográfica, de abordagem qualitativa, amparados pelos estudos de Antunes (2007), Bagno (2013), Geraldi (2012), Martelotta (2013), Neves (2002), Perini (2010), Travaglia (2009), entre outros. Essa compreensão sobre o processo de ensino de gramática se divide em duas partes, na primeira, busca-se compreender as diferentes abordagens metodológicas de ensino, como a tradicional, a cognitiva, dentre outras. Já na segunda, são analisadas as concepções de gramática, desde a normativa a cognitiva funcional. Por fim, são apresentados posicionamentos acerca da necessidade de adoção de uma metodologia de abordagem do ensino de gramática na Educação Básica, que mais se adequa a atual conjuntura social, apresentando as contribuições dessa perspectiva metodológica para o ensino de gramática.
\end{abstract}

Palavras-chave: Ensino de Língua Portuguesa. Gramatica. Educação Básica. Metodologia de ensino.

ABSTRACT: This study discusses the teaching of grammar in Basic Education and how it can be developed in view of the different theoretical and methodological concepts that support the teaching practices of the mother tongue at school. It is pointed out, in face of this scenario, for the possibility of teaching grammar in a reflexive way for the student, moving away from the traditional teaching approach, with a structuralist base, which historically was based on school benches. The aim of this study, therefore, is to reflect on the teaching of the language and how the concept of grammar should be passed on to the student, without underestimating the other types of language that distance themselves from the standard norm, that is, teach grammar in a way that the subject

\footnotetext{
1 Mestranda em Letras - Estudos da Linguagem pela Universidade Federal do Piauí (UFPI). Graduada em Letras Português e Francês (UFPI). E-mail: damarysalves.1997@hotmail.com

${ }^{2}$ Doutorando em Linguística pela Universidade Estadual de Campinas (UNICAMP). Mestre em Letras - Estudos da Linguagem (UFPI). Professor Substituto da Universidade Estadual do Maranhão (UEMA). Coordenador de disciplinas do Centro de Educação Aberta e a Distância (CEAD/UFPI). E-mail: fcorenatolima@,hotmail.com
} 
respects and knows how to express himself in the face of linguistic variations in the face of different situations of language use, from cultured varieties, considered standard to less prestigious varieties, considered informal. Methodologically, we started with a bibliographic research, with a qualitative approach, supported by the studies of Antunes (2007), Bagno (2013), Geraldi (2012), Martelotta (2013), Neves (2002), Perini (2010), Travaglia ( 2009), among others. This understanding of the grammar teaching process is divided into two parts, in the first, it seeks to understand the different methodological approaches to teaching, such as traditional, cognitive, among others. In the second, grammar conceptions are analyzed, from normative to functional cognitive. Finally, positions are presented about the need to adopt a methodology to approach grammar teaching in Basic Education, which is more suited to the current social situation, presenting the contributions of this methodological perspective to grammar teaching.

Keywords: Portuguese Language Teaching. Grammar. Basic education. Teaching methodology.

\section{CONSIDERAÇÕES INICIAIS}

Ensinar eficientemente a língua e, portanto, a gramática é, acima de tudo, propiciar e conduzir a reflexão sobre o funcionamento da linguagem, e de uma maneira, afinal, óbvia: indo pelo uso linguístico, para chegar aos resultados de sentido. Afinal, as pessoas falam exercem a linguagem, usam a língua para produzir sentidos, e, desse modo, estudar gramática é, exatamente, pôr sob exame o exercício da linguagem, o uso da língua, afinal, a fala.

(NEVES, 2000, p. 52).

Este trabalho tem como tema o ensino de gramática na escola e como este pode ser desenvolvido, a partir da possibilidade de olhar essa variedade formal de uso da língua, de modo reflexivo, afastando-se de uma abordagem metodológica tradicional do ensino. A gramatica possui diferentes conceitos e dependendo daquele que a escola adotar, isso influenciará nas suas escolhas metodológicas.

Incialmente, para situar o contexto da discussão, cabe, junto a Irandé Antunes (2007, p. 25-26), buscar responder ao seguinte questionamento: “Que gramáticas existem?”

a) das regras que definem o funcionamento de determinada língua, como em: "a gramática do português"; nessa acepção, a gramática corresponde ao saber intuitivo que todo falante tem de sua própria língua, a qual tem sido chamada de "gramática internalizada";

b) das regras que definem o funcionamento de determinada norma, como em: "a gramática da norma culta", por exemplo;

c) de uma perspectiva de estudo, como em: "a gramática gerativa", "a gramática estruturalista", "a gramática funcionalista”; ou uma tendência histórica de abordagem, como em: "a gramática tradicional", por exemplo;

d) de uma disciplina escolar, como em: "aulas de gramática";

e) de um livro, como em: "a Gramática de Celso Cunha". (Grifo da autora) 
Considerando a multiplicidade de coisas a que cada uma dessas acepções referem, neste estudo, aborda-se àquelas relacionadas ao ensino. Por isso, objetiva-se fazer uma reflexão sobre o ensino de gramática na escola de Educação Básica, elucidando as diversas abordagens metodológicas de ensino. Pretende também, desmitificar que não existe só uma concepção de gramática, que, nesse caso, as concepções vão além da gramática normativa. O referencial teórico tem como base, os estudos de Antunes (2007), Bagno (2013), Geraldi (2012), Martelotta (2013), Neves (2002), Perini (2010), Travaglia (2009), entre outros.

A metodologia utilizada é uma pesquisa bibliográfica, de caráter qualitativo. Na primeira etapa do estudo, são explicadas algumas abordagens metodológicas, como a abordagem tradicional, a abordagem comportamentalista, a abordagem humanista, a abordagem cognitivista e a abordagem sociocultural. E, na segunda, são explanadas as várias concepções de gramática no contexto da escola de Educação Básica, desde a gramática normativa a gramática cognitivo-funcional, por fim, são expostas as reflexões relevantes sobre a abordagem metodológica juntamente com as concepções de gramática, que mais se adequam a sociedade atual.

\section{ENSINO DE LÍNGUA PORTUGUESA NA ESCOLA DE EDUCAÇÃO BÁSICA: DAS ABORDAGENS TEÓRICO-METODOLÓGICAS}

A língua é resultado da necessidade social de se expressar de diferentes formas e nos mais diversos contextos. Levando em consideração que cada indivíduo possui suas particularidades, existem também, formas diversas de realizar o ensino e aprendizagem, que devem ser pensadas no momento que se decide qual metodologia será utilizada para atingir um determinado fim.

De acordo com Geraldi (2012), toda e qualquer metodologia de ensino articula-se a uma opção política, desde o conteúdo a ser ensinado, a bibliografia escolhida, devendo antes desses posicionamentos se levantar questões como: "para que ensinamos o que ensinamos?" O que ensinar?" Pois não se deve esquecer as vantagens de discutir como, quando e o que ensinar.

É indispensável que o professor realize uma reflexão sobre o tipo de ensino que deve utilizar em suas aulas. De acordo com Travaglia (2009, p. 38-40) seguindo os pressupostos de Halliday, Mcintosh e Strevens (1974), o ensino de uma língua é realizado de três formas: o prescritivo, o descritivo e o produtivo.

A forma de ensino prescritiva está relacionada a gramática normativa, que privilegia o ensino da norma culta e seus objetivos estão direcionados ao ensino de língua materna, 
privilegiando a variedade escrita da língua. "O ensino prescritivo objetiva levar o aluno a substituir seus próprios padrões de atividade linguística considerados errados/inaceitáveis por outros considerados corretos/aceitáveis" (TRAVAGLIA, 2009, p. 38). Essa fora é considerado também proscritiva, pois, ao dizer o que fazer, diz ao mesmo tempo, o que não fazer.

A forma descritiva discursa sobre habilidades já adquiridas, sem que estas sejam alteradas, e como são utilizadas, se preocupa em mostrar como a linguagem funciona. Portanto, trata "como a linguagem funciona e como determinada língua em particular funciona. Fala de habilidades já adquiridas, sem procurar alterá-las" (TRAVAGLIA, 2009, p. 39).

Por fim o ensino produtivo é o que objetiva o conhecimento de novas habilidades linguísticas, possibilita, dessa forma, ao aluno a compreensão do uso da língua materna de maneira consciente. É, portanto, o "mais adequado" ao objetivo de ensino básico da Língua Portuguesa: ampliar a competência comunicativa do aluno.

Esses três tipos de ensino influenciam as abordagens metodológicas adotadas. Estas, com o passar dos anos, sofreram algumas modificações, a fim de acompanhar a evolução socioeconômica de cada geração, considerando o fato de que o capital sempre influenciou nas metodologias e nos conteúdos a serem estudados. De acordo com Campos (2016), vive-se em uma era que a "maquina" é substituída pela "informação", a "fábrica" pelo "shopping center", e o "contato de pessoas" substituído pela "imagem e vídeo". Nisso, há de se refletir até que ponto essas transformações tecnológicas podem interferir (ou até substituir) sobre o potencial cognitivo e humano e o contato entre as pessoas. No dizer de Costa (2010, p. 92):

\footnotetext{
A sociedade pós-moderna trouxe consigo a imposição de uma nova forma de organização social, de concepções de espaço e tempo diferenciadas, hábitos de consumo engessadores e padronizadores das condutas sociais: os indivíduos são igualados e coisificados diante da tecnologia.
}

Face essa realidade, a educação deve acompanhar as mudanças sociais que o capital comanda, estando pois, numa era da informação. A escola deve estar preparada para ministrar um ensino capaz de formar sujeitos devidamente hábeis para receber informações, ou seja, interpretar a mensagem, e também, que saibam elaborar adequadamente a informação, tendo em vista que vive-se em um período de globalização.

Há diferentes metodologias de ensino, pode acontecer até que muitas delas possam ser utilizadas ao mesmo tempo. De acordo com Mizukami (2016), pode-se denominar os tipos de abordagens no processo de ensino, como: a tradicional, a comportamentalista, a humanista, a cognitivista e a sociocultural. 
Abordagem tradicional: caracterizada pela preocupação com os conhecimentos passados ao longo dos anos, por meio de um ensino voltado para o que é externo ao aluno, como o programa, as disciplinas e o professor (MIZUKAMI, 2016).

Essa concepção, conforme Saviani (2008 [1983]) propõe que a função do professor é assegurar que o conhecimento seja alcançado, independente da vontade do aluno, isso supõe que suas manifestações e participações estejam reduzidas. Freire alerta (1987) que essa sociedade utiliza um sistema de ensino fundado na "educação bancária", que irá "depositar" no aluno os conhecimentos, as informações, os dados, os fatos etc. Ou seja, cabe meramente ao indivíduo memorizar os conhecimentos passados, que costumam ser perpetuados ao longo de gerações.

Abordagem comportamentalista: também chamada de abordagem behaviorista, da ênfase em fatos objetivos. A teoria behaviorista teve início com Leonard Bloomfield (1887-1949) e, posteriormente, com Burrhus Frederic Skinner (1904-1990), que visavam a investigação do comportamento humano. Acreditando que ao conhecer o comportamento humano, seria possível controlá-lo (MIZUKAMI, 2016).

Os comportamentalistas julgam a experimentação como fundamento para o conhecimento, pois dão ênfase ao empirismo. Eles acreditam que o homem é consequência das influencias ou forças do meio ambiente que fazem parte. O ideal é transferir aos indivíduos o controle da situação que vive, para que estes se tornem auto controláveis e autossuficientes (MIZUKAMI, 2016).

Defende que o comportamento pode ser controlado com a observação do que denominou de “estimulo, resposta e reforço". O estimulo é dado pelo ambiente, ou seja, a situação submetida ao indivíduo, é o que o conduzirá a uma resposta ao estimulo, e o reforço é algo que fortalecerá a resposta dada (MIZUKAMI, 2016).

Dessa forma, os professores que seguem a abordagem metodológica comportamentalista fazem uma observação de seus alunos, reforçando as respostas vantajosas de seu ponto de vista, para que as respostas desejadas sejam repetidas. É nessa abordagem que surge a individualização do ensino, com os propósitos: especificar os objetivos, envolvimento com o aluno, controle das contingencias, feedbacks, e a apresentação do material respeitando o ritmo individual do aluno (MIZUKAMI, 2016).

Abordagem humanista: dá ênfase ao sujeito, se preocupa com suas relações interpessoais e o resultado desta. Considera a construção da personalidade do indivíduo e as coisas que estão inseridas nesse processo, como a vida psicológica e emocional do sujeito. Nessa perspectiva, tem-se a preocupação com a parte interna do indivíduo, como a auto aceitação e as 
preparação para a autenticidade, que seria desenvolvida para a realidade individual e em grupo (MIZUKAMI, 2016).

O professor não é visto como alguém que se transmite o conteúdo, ele é um facilitador para aprendizagem. Isso implicaria, por exemplo, na abolição dos exames, das notas e do diploma. O sujeito tem sua subjetividade respeitada pela escola, que procura formar um indivíduo autônomo. Os objetivos educacionais não são vistos em seu aspecto formal, porém, não há a supressão do provimento das informações, pois as informações são buscadas pelos alunos, que deve ser capaz de fazer críticas, aperfeiçoamentos ou substituições. Para a avalição se recorre as teorias de Roger e Neill, que desprezam a padronização de artigos da aprendizagem e competências dos professores. Essa abordagem recorre a teorias de Roger para explicar que o indivíduo é capaz de julgar, a partir de seus critérios internos e externos, o conhecimento adquirido e fazer os devidos ajustamentos (MIZUKAMI, 2016).

Abordagem cognitivista: estar ligada a estudos centrados no indivíduo, no seu processo de aprendizagem, na capacidade de processar as informações que lhe foram passadas, a educação deve ser feita de forma que a criança não se sinta acuada pelo adulto, e que sejam realizadas atividades em grupo, visando a socialização dos alunos, nesse caso o termo "socialização" é utilizado no sentido de cooperação. A abordagem cognitivista visa a autonomia do aluno, que este consiga procurar soluções, e estimular novas técnicas de aprendizagem (MIZUKAMI, 2016).

A escola deve contribuir para o desenvolvimento do aluno e suas possibilidades de ação motora, verbal e mental, de maneira que, posteriormente este, possa contribuir por inovações sociocultural na coletividade. Para isso as principais atividades realizadas na escola devem esta voltada para o pensamento, como jogos de pensamento para o corpo e sentidos, atividades sociais, jogos de raciocínio lógico, teatro, ler e escrever, aritmética, ciência, dentre outras atividades, que visem a estimulação do pensamento (MIZUKAMI, 2016).

Abordagem sociocultural: segundo Mizukami (2016), essa abordagem se preocupa com os aspectos socioculturais dos indivíduos. Um dos primeiros estudiosos a propor esse tipo de abordagem foi Paulo Freire, que se preocupava com a cultura. Ele considerava que a escola possui um contexto histórico e, portanto, deve ser compreendida, pensando em como o poder se estabelece na sociedade e se perguntar a serviço de quem a escola está. A abordagem sociocultural proposta por Paulo Freire (2001) é engajada na libertação de uma educação opressora, pois, nesse caso, os indivíduos devem fazer parte de uma educação que respeite seu contexto cultural, estabelecendo uma aprendizagem mútua entre aluno e professor. Há, desse modo, a preocupação com a superação do oprimido, por meio do diálogo. 


\section{CONCEPÇÕES DE GRAMÁTICA E ENSINO DE LÍNGUA PORTUGUESA}

Para alguns, a gramatica é apenas um conjunto de regras da língua para falar e escrever de forma adequada. Porém, o conceito de gramática pode ir além de um conjunto de regras. De acordo com Perini (2010), a escola tem o dever de introduzir ciência aos alunos, recorrendo ao conceito de que para a ciência, não há verdade absoluta, posto que as teorias cientificas podem ser questionadas, algo que pode ser repensado. Desse modo, as concepções de gramática se modificam com o tempo.

Martelotta (2013) denomina cinco concepções de gramática como: gramática tradicional, gramática histórico-comparativa, gramática estrutural, gramática gerativa e gramática cognitivofuncional.

Gramática tradicional: essa gramática também é conhecida como gramática normativa, tem sua origem em uma tradição de estudos filosóficos que teve início na Grécia Antiga, essa gramática "concebe" as formas "corretas" da língua, dessa forma abonam as formas que consideram “erradas”, adotando apenas a visão parcial da língua (MARTELOTTA, 2013).

Para Bechara (2006), a gramática normativa não deve ser considerada uma ciência, visto que nessa concepção a gramática é um conjunto de regras que não podem ser contestadas, em contrapartida, a ciência é algo que pode ser reestruturado.

De acordo Travaglia (2009), essa gramática normativa é um conjunto de normas a serem seguidas por quem deseja falar e escrever na norma culta, privilegiando apenas a variedade padrão da língua, se preocupando mais com a língua escrita, dando pouca importância a fala, que é considerada idêntica a escrita. Esse tipo de gramática é o que regulamenta o uso da língua na sociedade, diferente da gramática descritiva, ela não se preocupa em descrever os fatos, a gramatica normativa transforma os fatos da variedade culta da língua em regras. Geralmente, esse tipo de gramática está ligado a abordagem tradicional do ensino, sendo este, a forma mais comum na utilizada nas escolas.

Gramática histórico-comparativa: de acordo com Martelotta (2013), essa abordagem se desenvolveu na primeira metade do século XIX e teve início a partir da comprovação de semelhanças nas línguas.

[...] Essa abordagem dos fenômenos da língua surgiu a partir da constatação de grande semelhança do sânscrito, língua antiga da Índia, com o latim, com o grego e com a grande quantidade de línguas europeias. Essa semelhança pode ser ilustrada com os termos correspondentes ao sentido da palavra portuguesa "mãe" (mulher que gera filhos): maatar, em sânscrito; mäter, em latim; mètèr, em 
grego; em inglês, mutter, em alemão. (MARTELOT'TA, 2013, p. 47-48) (Grifos do autor)

Ainda segundo o autor, essa gramática teve início com o intuito de comparar as línguas de origem em comum para encontrar a estrutura da língua da qual derivaram, mas a gramática histórico-comparativa foi além disso, revelando que as línguas são mutáveis e mostrando que uma análise histórica é mais adequada que uma análise filosófica, rompendo com a tradição gramatical grega. Entretanto, essa visão comparatista não conseguiu fundamentar uma teoria sobre a estrutura do funcionamento das línguas naturais, conseguindo apenas, descrever processos de analogias e empréstimos, pois, como Saussure (2012 [1916]) ressalta mais tarde, os comparatistas analisavam a língua e elementos isolados, desconsiderando as transformações dentro do sistema linguístico que fazem parte.

Gramática estrutural: essa corrente se estabeleceu na primeira metade do século XX, tendo como base os estudos de Leonard Bloomfield nos Estados Unidos e de Ferdinand de Saussure, na Europa, com a publicação póstuma do livro Curso de Linguística Geral em 1916. Saussure conceituou langue e parole e propôs a langue como objeto de estudo da Linguística, ao retirar a parole, deixa de lado os estudos de natureza estrutural. Na visão de Martelotta (2013, p. 53), 'Saussure propunha que a langue constitui um sistema linguístico de base social que é utilizado como meio de comunicação pelos membros de a determinada comunidade".

[...] ao caracterizar o conceito de langue, empregou o termo sistema com uma intenção muito clara: queria demostrar que os elementos de uma língua não estão isolados, mas formam um conjunto solidário. [...] Essa proposta constitui base de toda a linguística estrutural: aceitando a ideia de que a língua é um sistema, cumpre analisar sua estrutura, ou seja, como esse sistema se organiza. Daí surgiram os termos "gramática estrutural" e "estruturalismo". (MARTELOTTA, 2013, p. 54)

Os estruturalistas ao analisar uma determinada língua, estão pois, analisando sua estrutura, ou seja, os elementos que formam o sistema da língua e a organização desses elementos, e como esses estes se unem para formar unidades maiores.

Gramática gerativa: surge em 1957, com o livro Estruturas sintáticas, de Noam Chomsky. Esses estudos estavam baseados na crítica ao behaviorismo, na obra de Skinner, Verbal Behavior, também de 1957 (MARTELOTTA, 2013).

Segundo Martelotta (2013), essa abordagem da ênfase aos estudos de natureza biológica. Chomsky destaca o processo mental da espécie, o componente criativo necessário para linguagem. Para ativar o funcionamento desse órgão mental, a pessoa será exposta a estímulos externos, como as experiências que estimulam a faculdade da linguagem. Há dois pontos importantes para 
caracterização dessa corrente teórica, o primeiro é denominado princípio do inatismo, que é "um conjunto de princípios gerais que impõe limites na variação entre línguas e que se manifestam como dados universais, ou seja, presentes em todas as línguas do mundo” (MARTELOTTA, 2013, p. 59). O outro princípio é o princípio da modularidade da mente, a mente é constituída de módulos ou partes, conceituados "como sistemas cognitivos diferentes, que trabalham separadamente" (p. 59). É nessa linha de estudos que se introduz a noção de cognição.

Gramática cognitivo-funcional: o termo para essa gramática é utilizado para designar um conjunto de propostas metodológicas. A gramática cognitiva-funcional possui alguns pontos em comum com outras escolas, por exemplo, a gramática estrutural e a gramática gerativa, estudando a estrutura gramatical e analisando a situação de comunicação por inteiro, os eventos de fala, seus participantes e o contexto do discurso, considerando também que o discurso necessita da gramática para se constituir e a gramática se alimenta do discurso (MARTELOTTA, 2013).

Nessa concepção, a mente e o corpo não são vistos separadamente, o que denomina a perspectiva filosófica de realismo corporificado, que tem três características básicas para compreensão; a primeira é que a abandona a dicotomia empirismo vs. racionalismo, pois acredita que existem conceptuais universais, e que esses conceptuais não definem de forma fechada o pensamento humano e se estabelece em situações reais de interação social (MARTELOTTA, 2013).

Conforme Martelotta (2013, p. 66-67), “admitindo a influência de fatores externos sobre estrutura linguística, a linguística cognitivo-funcional associa os conceitos humanos à época, à cultura e até mesmo a tendências individuais, que se manifestam no uso da língua."

A segunda característica é que incorpora o método abdutivo-analógico, o qual estabelece novas hipóteses e novos insights teóricos, é visto como mecanismo inerente para os processos de aquisição da linguagem (MARTELOTTA, 2013).

A terceira característica dessa corrente é que apresenta um caráter explicativo e universalista, parte de um modo explicativo e não apenas descritivo dos fenômenos da linguagem (MARTELOTTA, 2013).

A gramática cognitivo-funcional se propõe então, a estudar os fenômenos da linguagem e vários aspectos, propõe um equilíbrio na relação existente entre biologia e cultura para a compreensão da estrutura da língua. 


\section{SOBRE LÍNGUA, GRAMÁTICA E ENSINO: UM ENFOQUE NA FUNCIONALIDADE DA LINGUAGEM}

O ensino de gramática na escola geralmente se faz com a intenção que os alunos falem e escrevam bem. Porém, de acordo com Marcos Bagno, em seu livro Preconceito linguístico: o que é, como se faz? (2013), isso é considerado um mito e que, apesar da gramatica normativa se propor ao ensino da norma culta, essa variedade da língua vai existir independente da gramática, e, portanto, a concretização dessa imposição da gramática normativa se caracteriza por mecanismos ideológicos.

Neves (2002), afirma que a gramática se encarrega da produção de sentido, é portanto, a língua em seu funcionamento. Dessa forma, o que se decora nas aulas de gramática na escola, não é considerado gramática, pois a língua não funciona dessa maneira, como um conjunto unilateral e inflexível de normas.

Um ponto importante é extinguir a frase comumente ouvida por falantes da Língua Portuguesa "falar português é difícil", como se a pessoa não soubesse falar português, desconsiderando qualquer variedade da língua que não esteja conforme as regras estabelecidas pela gramatica normativa, pois a escola passou erroneamente somente essa visão da língua. Outro mito que Bagno (2013) explica é o de só se falar corretamente português em Portugal, e que o lugar melhor se que se fala português no Brasil é o Maranhão, pois não há o uso do pronome $t u$, com forma verbal clássica, também utilizada em Portugal. Bagno (2013) afirma ainda, que não existe nenhuma variedade da língua "melhor", "mais correta", "mais pura", "mais bonitas", e todas as variações linguísticas existentes, devem ser respeitadas, e que estas variações vazem parte da nossa preciosa cultura.

A escola não deve fazer com que os indivíduos acredite que a única maneira aceitável de se falar seja a norma culta. Isso também vale tanto para o ensino de língua materna, como de língua estrangeira, pois em ambos, há as ditas variedades linguísticas, como variações regionais, históricas, entre outras, que são a identidade dos indivíduos que a utilizam e isso não pode ser menosprezado pela escola.

Uma alternativa possível a minimização desse problema na escola básica é, segundo Lima (2017), tratar dessas questões, logo na formação inicial de professores de Letras - Língua Portuguesa e Literaturas, levando-os, desde a universidade, a terem contato com reflexões teóricas semelhantes a esta, apresentada neste estudo. Para o autor:

Quando se aponta para as abordagens linguísticas, considera-se que elas precisam ser meio de examinar as formas como a língua e a sociedade articulam-se. O resultado dessa aproximação possibilitará o entendimento sobre formas de funcionamento interno e externo do código; seus processos de evolução e 
mudança; as forças de coerção social que atravessam o ensino da língua na escola; o papel da escola, representada primordialmente pela figura do professor; a superação de perspectivas estruturais que fragmentam o ensino, considerando-se a necessidade da adoção de uma abordagem interacional, em que considere o contexto e a situação comunicativa; entre outras questões problematizadoras dessa realidade. (LIMA, 2017, p. 104)

Por meio dessa conduta, talvez seja possível

[...] desarraigar, os modelos de ensino verticais e tradicionais, baseados em abstrações teóricas e conceituais distantes da realidade do aluno, que historicamente construíram a história do ensino da leitura e da escrita na escola básica, e em substituição a eles, adotar procedimentos didático-pedagógicos aplicados aos usos da língua no cotidiano, em circunstâncias de manifestações híbridas desses usos, reconhecidas e valorizadas a partir da heterogeneidade das práticas letradas na sociedade e nas quais os sujeitos assumem lugar de participação e interação social dialógicas. (LIMA; BORGES, 2018, p. 90)

\section{CONSIDERAÇÕES FINAIS}

De posse do manancial teórico explorado neste estudo, bem como, das possibilidades de exploração pedagógica que a língua oferece em sala de aula de Educação Básica, no ensino de gramática, sobretudo, considera-se que, a gramática cognitivo-funcional é a que mais se adequa as necessidades dos indivíduos que desejam adquirir conhecimentos sobre a linguagem em vários aspectos, sejam eles, no sentido estrutural da língua ou a fatores externos a estrutura linguística, levando em consideração o processamento cognitivo do indivíduo, associando os conceitos humanos da época e os fatores culturais.

A gramática cognitivo-funcional só é possível ser utilizada pela escola que possua metodologias de ensino e aprendizagem que possibilitem a autonomia dos indivíduos que a constituem. A abordagem cognitivista pode contribuir nessa jornada de ensino e aprendizagem, com atividades centradas no desenvolvimento do pensamento, como teatro, jogos de pensamento, dentre outras atividades que estimulem a criatividade. Essa gramática possui o método abdutivoanalógico, que fomenta a busca de novas hipóteses e utiliza uma linguagem explicativa.

Com isso, não se está abrindo mão ou rejeitando o ensino da gramática normativa, ministrada em muitas escolas de Educação Básica, muito pelo contrário, a crítica recai sobre o modo como esse ensino ocorre, sendo definido por muitos, apenas como "muito difícil de aprender", porque, de certa forma, os indivíduos tentavam apenas a sua "memorização", com um ensino de caráter descritivo e não de caráter explicativo, como na gramática cognitivo-funcional, que busca explicar seus conceitos. 
Não se deve abrir mão do ensino da forma padrão, considerada a norma culta da língua, o importante é abordar esse conhecimento para o aluno de forma explicativa, de maneira contextualizada, mostrando a importância do indivíduo se tornar alguém capacitado para falar e escrever na variedade da língua que se propuser, sem preconceitos linguísticos. É de grande valor para um aprendizado eficaz, deixar claro para o aluno o motivo de se estudar gramática, estimulando sua capacidade de ampliar a competência comunicativa.

\section{REFERÊNCIAS}

ANTUNES, Irandé. Muito além da gramática: por um ensino de línguas sem pedras no caminho. São Paulo: Parábola, 2007.

BAGNO, Marcos. Preconceito linguístico: o que é, como se faz? 55. ed. São Paulo: Loyola, 2013.

BECHARA, Evanildo. A moderna gramática do português. 37. ed. Rio de Janeiro: Lucerna, 2006.

CAMPOS, Casemiro de Medeiros. Saberes docentes e autonomia dos professores. 6. ed. Petrópolis: Vozes, 2016.

COSTA, Mila Batista Leite Corrêa da. As relações de trabalho, a máquina e o fato. Rev. Trib.

Reg. Trab. 3a Reg., Belo Horizonte, v. 51, n. 81, p. 91-105, jan./jun., 2010.

FREIRE, Paulo. Conscientização: teoria e prática da libertação: uma introdução ao pensamento de Paulo Freire. 3. ed. São Paulo: Centauro, 2001.

FREIRE, Paulo. Pedagogia do oprimido. 17. ed. Rio de Janeiro: Paz e Terra, 1987.

GERALDI, João Wanderley. Concepções de linguagem e ensino de Português. In: GERALDI, João Wanderley (Org.). O texto na sala de aula. São Paulo: Anglo, 2012. p. 39-46.

LIMA, Francisco Renato. Uma reunião teórica entre língua, linguagem e linguística: entrelaçando olhares para a formação do professor e o ensino de Língua Portuguesa. Miguilim - Revista Eletrônica do Netlli, Crato, v. 6, n. 3, p. 91-112, set.-dez., 2017.

LIMA, Francisco Renato; BORGES, Vanessa Raquel Soares. Ensino da língua materna e letramento social: entrecruzando olhares a partir dos Parâmetros Curriculares Nacionais. In: LIMA, Francisco Renato; SILVA, Marcos Helam Alves da (Orgs.). Ensino de língua em contextos aplicados: perspectivas funcionais. Teresina: EDUFPI, 2018. p. 79-107.

MARTELOTTA, Mario Eduardo. Conceitos de gramática. In: MARTELOTTA, Mario Eduardo. Manual de Linguística. 2. ed. São Paulo: Contexto, 2013. p. 43-70. 
MIZUKAMI, Maria da Graça Nicoletti. Ensino: as abordagens do processo. São Paulo. EPU, 2016.

NEVES, Maria Helena de Moura. A gramática: conhecimento e ensino. In: AZEREDO, José Carlos de. (Org.). Língua Portuguesa em debate: conhecimento e ensino. Petrópolis: Vozes, 2000. p. 52-73.

NEVES, Maria Helena de Moura. A gramática: história, teoria e análise, ensino. São Paulo: UNESP, 2002.

PERINI, Mário Alberto. Gramática do português brasileiro. São Paulo: Parábola, 2010.

SAVIANI, Demerval. Escola e democracia. Edição comemorativa da $40^{\mathrm{a}}$ ed. Campinas: Autores Associados, 2008. [1983].

SAUSSURE, Ferdinand. Curso de Linguística Geral. Trad. Antônio Chelini, José Paulo Paes, Izidoro Blikstein. 28. ed. São Paulo: Cultrix, 2012. [1916].

TRAVAGLIA, Luiz Carlos. Gramática e interação: uma proposta para o ensino de gramática no $1^{\circ}$ e $2^{\circ}$ graus. 3. ed. São Paulo: Cortez, 2009. 